Article

\title{
Grinding Kinetics of Slag and Effect of Final Particle Size on the Compressive Strength of Alkali Activated Materials
}

\author{
Evangelos Petrakis ${ }^{1, *(\mathbb{D})}$, Vasiliki Karmali ${ }^{1}$, Georgios Bartzas ${ }^{2} \mathbb{( 1 )}$ and Konstantinos Komnitsas ${ }^{1}$ (I) \\ 1 Technical University of Crete, School of Mineral Resources Engineering, University Campus, \\ Kounoupidiana, 73100 Chania, Greece; vkarmali@isc.tuc.gr (V.K.); komni@mred.tuc.gr (K.K.) \\ 2 School of Mining and Metallurgical Engineering, National Technical University of Athens, \\ 15780 Zografos, Athens, Greece; gbartzas@metal.ntua.gr \\ * Correspondence: vpetraki@mred.tuc.gr; Tel.: +30-28210-37608
}

Received: 21 October 2019; Accepted: 16 November 2019; Published: 19 November 2019

\begin{abstract}
This study aims to model grinding of a Polish ferronickel slag and evaluate the particle size distributions (PSDs) of the products obtained after different grinding times. Then, selected products were alkali activated in order to investigate the effect of particle size on the compressive strength of the produced alkali activated materials (AAMs). Other parameters affecting alkali activation, i.e., temperature, curing, and ageing time were also examined. Among the different mathematical models used to simulate the particle size distribution, Rosin-Rammler (RR) was found to be the most suitable. When piecewise regression analysis was applied to experimental data it was found that the particle size distribution of the slag products exhibits multifractal character. In addition, grinding of slag exhibits non-first-order behavior and the reduction rate of each size is time dependent. The grinding rate and consequently the grinding efficiency increases when the particle size increases, but drops sharply near zero after prolonged grinding periods. Regarding alkali activation, it is deduced that among the parameters studied, particle size (and the respective specific surface area) of the raw slag product and curing temperature have the most noticeable impact on the compressive strength of the produced AAMs.
\end{abstract}

Keywords: particle size distribution; grinding kinetics; slag; alkali activated materials; compressive strength

\section{Introduction}

Very large quantities of slags are generated during steel, ferrous- and non-ferrous metal production. Even though a certain share of the produced slag volume is used in the construction sector, large quantities are not properly managed and are considered as sources of environmental pollution. Thus, the development of an integrated management scheme that can transform this resource into valuable products is of great importance [1,2].

Slags are mainly used for cement and concrete production. This utilization option eliminates environmental problems and contributes to the reduction of the environmental footprint of the construction sector. It is known that cement production is one of the most energy intensive processes, since it consumes $12 \%$ to $15 \%$ of the total industrial energy requirements and is responsible for $7 \%$ to $10 \%$ of the global $\mathrm{CO}_{2}$ emissions [3,4]. Other alternative options for slag management include its use in road construction as aggregate [5], and in recent years the production of alkali activated materials (AAMs), called inorganic polymers (IPs) or "geopolymers", can be used as construction materials or binders in the construction sector, thus improving its sustainability [6]. 
Alkaline activation, which is carried out with the use of $\mathrm{NaOH}, \mathrm{KOH}$, and $\mathrm{Na}_{2} \mathrm{SiO}_{3}$ solutions at relatively low temperature, is considered as a promising option for the management of various waste streams and the production of AAMs (alkali activated materials) exhibiting beneficial physico-chemical and thermal properties [7-12]. The potential of wastes for alkali activation depends on their content of aluminosilicates which defines their reactivity, the strength of the activating solution and the other synthesis conditions, mainly particle size of the raw material used, curing temperature, curing and ageing period [13,14].

So far various types of slags, rich in $\mathrm{Ca}$ or Fe, produced from various metal and steel production industries have been successfully alkali activated. Alkali activation involves the use of raw slags or their mixtures with other waste types to regulate their content of aluminosilicates and enable the formation of strong bonds [15-18]. It is mentioned that the produced structures may also exhibit other beneficial properties, including the sorption of contaminants from solutions and immobilization of hazardous ions $[19,20]$.

Slag, prior to its use in most applications, requires grinding which is an energy intensive process, characterized by high $\mathrm{CO}_{2}$ emissions and increased processing cost. In addition, grinding is a low-efficiency process because a large share of the consumed energy is absorbed by the device and only a small part is used for size reduction [21,22]. Considering these factors, the investigation of grinding kinetics of any raw material, including slag, is an important aspect.

Among the different approaches used to improve grinding efficiency, phenomenological grinding kinetics models based on population balance considerations are used. Population balance modeling is based on two functions, namely the breakage rate and the breakage function [23,24]. Many studies have reported the advantages of these functions $[25,26]$ and the variation of the kinetic model parameters under different mill operating conditions [27-32]. Another important issue associated with the grinding operation is the scale-up of ball mills based on laboratory test work [33].

The determination of the breakage rate for the mass fraction of feed size $R$ is based on the assumption that grinding follows a first-order law as reported in previous studies [22,24], according to Equation (1),

$$
\frac{d R}{d t}=-K \cdot R
$$

where $K$ is the grinding rate constant and $t$ is the grinding time.

Generally, the first-order hypothesis is the most widely used one to describe the grinding process in a ball mill, however, many researchers have observed that, in fact, the breakage rate slows down with increasing grinding time and deviates from the first-order; this breakage is called non-first-order [34-36].

In light of the non-first-order behavior Alyavdin proposed that the following formula (Equation (2)) can be used to describe the grinding process $[37,38]$,

$$
R=R_{0} \cdot e^{-K \cdot t^{M}}
$$

where $R_{0}$ is the mass fraction in the feed, and $M$ is a constant depending on the material properties and grinding conditions.

The present study aims, through batch grinding experiments, to model grinding and evaluate the effect of grinding time on the particle size distribution of the slag products. Then, selected grinding products were alkali activated, and the effect of particle size, specific surface area, curing temperature, and ageing time on the properties of the produced AAMs was assessed. The novelty of the study is that it investigates in depth the grinding kinetics of an industrial waste and the effect of the particle size of the raw material for the production of AAMs, issues that so far have not been systematically investigated. 


\section{Mathematical Models for the Simulation of PSD}

In the literature and also in industrial practice, several models have been tested to simulate mathematically the particle size distribution (PSD) of the grinding products. These include log-normal, logistic, Gates-Gaudin-Schuhmann (GGS) and Rosin-Rammler (RR) distributions, while truncated distributions, e.g., logarithmic distribution, Gaudin-Meloy, log-normal and the truncated version of RR distribution can also be used to describe particulate materials $[39,40]$. In addition, fractal geometry which is based on the idea of self-similarity is also widely used for describing various complex natural phenomena, including particle size distribution [41,42]. Other studies have used the Swrebec distribution model as an alternative to traditional distributions because of its goodness-of-fit in both coarse and fine size ranges [43,44]. The Rosin-Rammler distribution that was used in the present study is expressed by Equation (3),

$$
P=100-100 \cdot \exp \left[-\left(\frac{x}{x^{\prime}}\right)^{n}\right]
$$

where $x$ is the screen aperture size, $P$ is the mass or volume (in \%) finer than size $x, x^{\prime}$ is the size modulus (63.2\% passing-screen size), and $n$ is the distribution modulus (index of uniformity). The higher the $n$ value the more uniform is the distribution [45]. The RR distribution can be transformed to:

$$
\log \log \left(\frac{100}{100-P}\right)=n \cdot \log x+\left(\log \log e-n \cdot \log x^{\prime}\right)
$$

Equation (4) indicates that if the data follow the RR distribution, the plot of $\log \log (100 /(100-P))$ versus $\log x$ will be a straight line from which $n$ and $x^{\prime}$ can be calculated.

The PSD of the grinding products can be also mathematically described by the logistic distribution as follows:

$$
P=\frac{100}{1+\left(\frac{x_{50}}{x}\right)^{\lambda}}
$$

where $x_{50}$ is the $50 \%$ passing-screen size and $\lambda(>0)$ is the distribution modulus (sharpness index). Equation (5) can be transformed into a straight line as follows:

$$
\log \left(\frac{100}{P}-1\right)=-\lambda \cdot \log x+\left(\lambda \cdot \log x_{50}\right)
$$

From the straight line of Equation (6) $\lambda$ and $x_{50}$ can be calculated.

The GGS model that was used in the present study is expressed by Equation (7),

$$
P=100 \cdot\left(\frac{x}{k}\right)^{m}
$$

where $k$ is the particle size modulus (maximum particle size) and $m$ is the distribution modulus (index of uniformity). Lower values of $m$ suggest the production of more fines and large particles, while as the value of $m$ increases the distribution gets narrower $[45,46]$.

The GGS model follows a power-law and is therefore equivalent to fractal distribution, as proposed by Turcotte [47]. Logarithmic transformation of Equation (7) results in a linear relationship between $\log P$ and $\log x$ from which $k$ and $m$ can be determined using linear regression analysis. Then, the fragmentation fractal dimension could be calculated as follows,

$$
D=3-m
$$

Since simple linear models may not fit the entire dataset, a piecewise approximation could be used for the description of the PSD of the grinding products [48,49]. Based on this, it is assumed that there could be two intervals of particle sizes separated by a critical size. This could mean that the $\log$-transformed data of Equation (7) would yield two straight lines, separated by a breakpoint $\left(\log x_{\mathfrak{b}}\right)$ defined as the transition point between two particle intervals, 


$$
\log P=m_{1} \cdot \log x+b_{1} \cdot\left(\log x \leq \log x_{b}\right)+m_{2} \cdot \log x+b_{2} \cdot\left(\log x>\log x_{b}\right)
$$

where $m_{1}$ and $m_{2}$ are the slopes and $b_{1}$ and $b_{2}$ are the intercepts of the straight lines. Each term in parenthesis represents a logical operation, i.e., if the term is true it will get the value 1 , while if it is false it will get the value 0 .

\section{Materials and Methods}

The material used in this study is slag produced from the pyrometallurgical treatment of Ni-bearing silicate ores in Szklary, southwestern Poland [50]. Its chemical composition, as obtained by X-ray fluorescence in the form of oxides is shown in Table 1. The main mineralogical phases present, as obtained by X-ray diffraction (XRD), were quartz $\left(\mathrm{SiO}_{2}\right)$, hedenbergite $\left(\mathrm{Ca}(\mathrm{Fe}, \mathrm{Mg})\left(\mathrm{SiO}_{3}\right)_{2}\right)$, fayalite $\left(\mathrm{Fe}_{2} \mathrm{SiO}_{4}\right)$, diopside $\left(\mathrm{CaMgSi}_{2} \mathrm{O}_{6}\right)$, and magnetite $\left(\mathrm{Fe}_{3} \mathrm{O}_{4}\right)$, while hatrurite $\left(\mathrm{Ca}_{3} \mathrm{SiO}_{5}\right)$ is present as a minor phase. More data about the origin and the characteristics of this slag can be found in a previous recent study [2].

The received sample, approximately $200 \mathrm{~kg}$, with a particle size of $-100 \mathrm{~mm}$ was homogenized by the cone and quarter method, and a representative quantity was crushed to less than $0.850 \mathrm{~mm}$ using a Fritsch type jaw crusher (Fritsch pulverisette 1, Fritsch GmbH, Idar-Oberstein, Germany) for primary and a cone crusher (Sepor, Wilmington, NC, USA) for secondary crushing. The particle size distribution of the feed material and grinding product was determined using a Malvern type $S$ Mastersizer (Malvern Instruments, Malvern, UK) (size range: 0.05 to $850 \mu \mathrm{m}$ ) and laser diffraction (LD) technique. LD was also used for the estimation of the specific surface area (SSA) of the feed material and grinding products using Equation (10).

$$
S_{w}=\left(\frac{f}{k}\right) \cdot \frac{1}{\rho_{p} \cdot D[3,2]}
$$

$S_{\mathrm{W}}$ is the specific surface area, $\rho_{\mathrm{p}}$ is the particle density, D[3,2] is the surface area mean (Sauter mean diameter), and $f, k$ are the surface and volume coefficients (for spheres $f / k=6$ ).

Table 1. Chemical composition (wt \%) of slag.

\begin{tabular}{ccccccccccccc}
\hline $\mathrm{Fe}_{2} \mathrm{O}_{3}$ & $\mathrm{SiO}_{2}$ & $\mathrm{Al}_{2} \mathrm{O}_{3}$ & $\mathrm{Cr}_{2} \mathrm{O}_{3}$ & $\mathbf{M g O}$ & $\mathbf{N i O}$ & $\mathrm{K}_{2} \mathrm{O}$ & $\mathrm{TiO}_{2}$ & $\mathrm{CoO}$ & $\mathrm{MnO}$ & $\mathrm{CaO}$ & $\mathbf{P}_{2} \mathrm{O}_{5}$ & Total \\
\hline 40.62 & 30.18 & 7.60 & 1.98 & 1.80 & 0.95 & 0.89 & 0.69 & 0.03 & 0.28 & 13.0 & 0.02 & 98.01 \\
\hline
\end{tabular}

LD involves the detection of the angular distribution of scattered light produced by a laser beam which passes through a dispersed particulate sample [51]. The data of the angular scattering intensity is then analyzed and the particle sizes are calculated using the Mie theory of light scattering and expressed as the volume equivalent sphere diameter [52,53]. Thus, since LD assumes a specific geometry for the particles without taking into consideration the particle shape, the Brunauer-Emmett-Teller (BET) nitrogen adsorption method (using a Quantachrome Nova 2200 analyser, Anton Paar QuantaTec Inc., Boynton Beach, FL, USA) was considered for the determination of SSA [54].

The techniques used for characterizing raw slag and the produced AAMs are (i) X-ray powder diffraction, for the identification of the mineral phases using a D8 Advance type (-AXS, Karlsruhe, Germany) diffractometer and (ii) X-ray fluorescence, for the chemical analysis using a Bruker S2 Ranger Energy-dispersive ED-XRF (Bruker, Karlsruhe, Germany) Spectrometer. Scanning electron microscopy (SEM) was also used to define the morphology of the raw slag and the grinding products, using a JEOL 6380LV microscope (JEOL Ltd., Tokyo, Japan) equipped with an Oxford INCA energy dispersive X-ray spectrometer (EDS).

Grinding tests were carried out in a ball mill (Sepor, Los Angeles, CA, USA) with dimensions of $\mathrm{L} \times \mathrm{D}=166 \times 204 \mathrm{~mm}$ using different grinding times $(15,30,45,60,90$, and $120 \mathrm{~min})$ under dry conditions. Stainless steel balls $\left(\rho_{\mathrm{b}}=7.85 \mathrm{~g} / \mathrm{cm}^{3}\right)$ with three different sizes, i.e., 40, 25.4, and 
$12.7 \mathrm{~mm}$ were used as grinding media. The total ball mass was almost constant at each ball size used corresponding to ball filling volume $J=20 \%$, while the material filling volume $f_{\mathrm{c}}$ was $4 \%$. This means that $50 \%$ of the interstitial filling $U$ of the void spaces of the balls was filled with material, according to Equation (11). The mill specification data and test conditions are shown in Table 2.

$$
U=\frac{f_{c}}{0.4 \cdot J}
$$

Table 2. Mill specification data and test conditions.

\begin{tabular}{ccc}
\hline & Diameter, $D(\mathrm{~cm})$ & 20.4 \\
Length, $L(\mathrm{~cm})$ & 16.6 \\
Mill & Volume, $V\left(\mathrm{~cm}^{3}\right)$ & 5423 \\
& Operational speed, $N(\mathrm{rpm})$ & 66 \\
& Critical speed, $N_{\mathrm{c}}(\mathrm{rpm})$ & 93.7 \\
\hline \multirow{4}{*}{ Balls } & Diameter, $d(\mathrm{~mm})$ & $40,25.4,12.7$ \\
& Number & $6,28,202$ \\
& Weight $(\mathrm{g})$ & 7.85 \\
& Density $\left(\mathrm{g} / \mathrm{cm}^{3}\right)$ & 40 \\
& Porosity $(\%)$ & 20 \\
\hline \multirow{2}{*}{ Material } & Ball filling volume, $J(\%)$ & 1.67 \\
& Bulk density $\left(\mathrm{g} / \mathrm{cm}^{3}\right)$ & 4 \\
& Material filling volume, $f_{\mathrm{c}}(\%)$ & 50 \\
\hline
\end{tabular}

The reactivity of the products obtained after 30,60, and 120 min of grinding was evaluated through leaching of $1.0 \mathrm{~g}$ of solids in $100 \mathrm{~mL}$ of $8 \mathrm{~mol} / \mathrm{L}(\mathrm{M}) \mathrm{NaOH}$ solution for $24 \mathrm{~h}$ at ambient temperature $\left(\sim 22{ }^{\circ} \mathrm{C}\right)$ under continuous magnetic stirring. After solid-liquid separation with the use of $0.45 \mu \mathrm{m}$ pore size membrane filters (PTFE, Chromafil, Macherey-Nagel GmbH and Co. Düren, Germany), the concentration of $\mathrm{Al}$ and $\mathrm{Si}$ in the eluate was determined using an Agilent 7500cx Inductively Coupled Plasma Mass Spectrometry (ICP-MS) (Agilent Technologies Inc., Santa Clara, CA, United States) equipped with an Agilent ASX-500 Autosampler.

The slag products obtained after 30,60, and $120 \mathrm{~min}$ of grinding were alkali activated using a mixture of sodium hydroxide $\left(\mathrm{NaOH}\right.$, Sigma Aldrich) and sodium silicate $\left(\mathrm{Na}_{2} \mathrm{SiO}_{3}, \mathrm{Merck}\right)$ as alkaline activating solution. Pellets (anhydrous) of $\mathrm{NaOH}$ dissolved in water to produce solutions with specific molarity, followed by the addition of sodium silicate solution $\left(8 \mathrm{wt} \% \mathrm{Na}_{2} \mathrm{O}, 27 \mathrm{wt} \% \mathrm{SiO}_{2}\right.$, and $65 \mathrm{wt} \%$ $\mathrm{H}_{2} \mathrm{O}$ ). The final solution was allowed to cool at ambient temperature for $24 \mathrm{~h}$ and then mixed under continuous stirring with each grinding product to obtain a paste. Six sets of samples were prepared in order to investigate the effect of slag particle size and curing temperature on the properties of the produced AAMs, while the liquid/solid (L/S) ratio was kept constant at 0.25 . The composition of the mixture was (wt \%): $80 \%$ slag, $16.7 \% 8 \mathrm{M} \mathrm{NaOH}$ solution and $3.3 \% \mathrm{Na}_{2} \mathrm{SiO}_{3}$. Under these conditions the molar ratio of $\mathrm{H}_{2} \mathrm{O} / \mathrm{Na}_{2} \mathrm{O}$ in the reactive paste was 12.9. According to the procedure followed, cubic metal molds ( $5 \mathrm{~cm}$ edge) were filled with the fresh paste and vibrated for compaction and removal of air voids. The molds remained at ambient temperature for a period of 3 to $9 \mathrm{~h}$ and when the paste hardened sufficiently the specimens were removed, sealed in plastic bags to avoid moisture loss, and cured for $24 \mathrm{~h}$ at either 60 or $80^{\circ} \mathrm{C}$ in a laboratory oven (Jeio Tech ON-02G, Seoul, Korea). After curing, specimens were allowed to cool at room temperature, and after the ageing periods of 7 and 28 days the compressive strength was determined using a Matest C123N load frame (Matest S.p.A, Treviolo, Bergamo, Italy). The experimental conditions used in this study were based on the results of a previous study carried out in the laboratory and involving the same slag [2]. All tests and measurements were carried out in triplicate and the average values are provided in this study. Finally, the apparent density, porosity, and water absorption of selected AAMs were determined based on the standard BS EN 1936 [55]. 


\section{Results and Discussion}

\subsection{Particle Morphology of Raw Slag and Grinding Products}

The particle morphology of the raw slag and the grinding products obtained after 30,60, and 120 min of grinding, as derived with the use of SEM at different magnifications, is shown in Figure 1a-e.
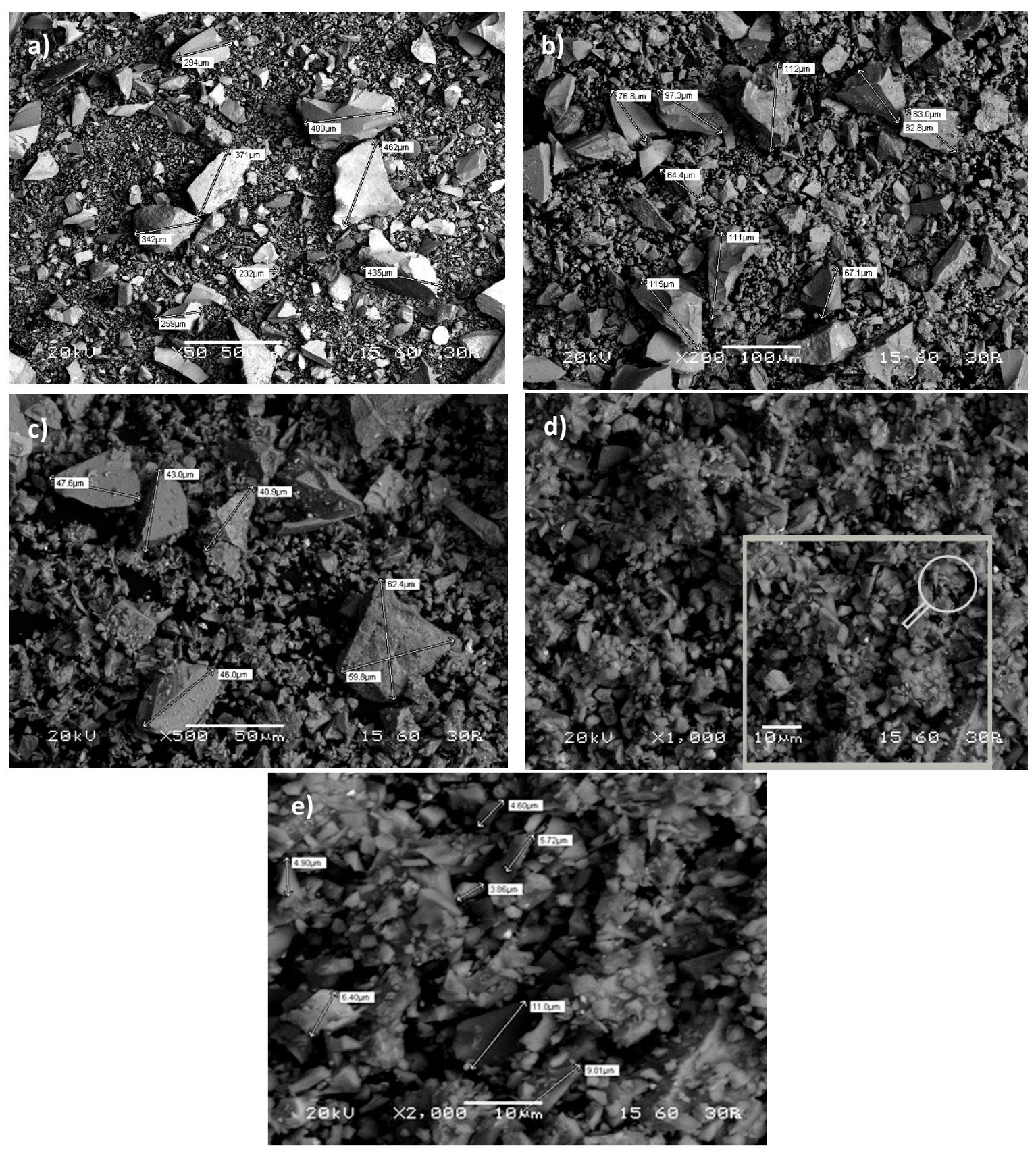

Figure 1. Morphology of particles: (a) raw slag, and after (b) $30 \mathrm{~min}$, (c) $60 \mathrm{~min}$, (d,e) $120 \mathrm{~min}$ of grinding.

The obtained results indicate that, in general, the particles of raw slag have a flat-face, and an irregular and elongated shape, while no spherical particles are observed (Figure 1a). A broad particle size distribution is observed for particles smaller than $\sim 500 \mu \mathrm{m}$. With increasing grinding time (30 to $60 \mathrm{~min}$ ) the particles become progressively finer while their morphology shape remains almost similar (Figure 1b,c). 
After prolonged grinding (120 min), even though finer particles are quite irregular, coarser particles tend to become more rounded due to their subjection to attrition (Figure 1d). At this stage, it is seen that particles are distinct and no agglomeration is observed. The evolution of particle morphology during grinding has been investigated in previous studies which reported that the type of material being ground, the mill type, as well as the mode of breakage may have a large impact on the shape of particles produced [56-58].

\subsection{Grinding Kinetics Modeling}

The particle size distributions of the feed (raw slag) and grinding products as a function of the grinding time are shown in Figure 2. It is seen that the particle size of the grinding product gradually decreases with the increase of grinding time. It is known that the degree to which finer particles are reduced depends on the mill, the material type, and the grinding conditions [58]. Figure 2 also shows that no particle agglomeration was observed even after $120 \mathrm{~min}$ of grinding, unlike the findings of previous studies which indicate potential agglomeration after long grinding periods $[59,60]$; the absence of agglomeration is due to the lack of clay minerals in the feed and is confirmed in Figure 1d which shows that particles are distinct.

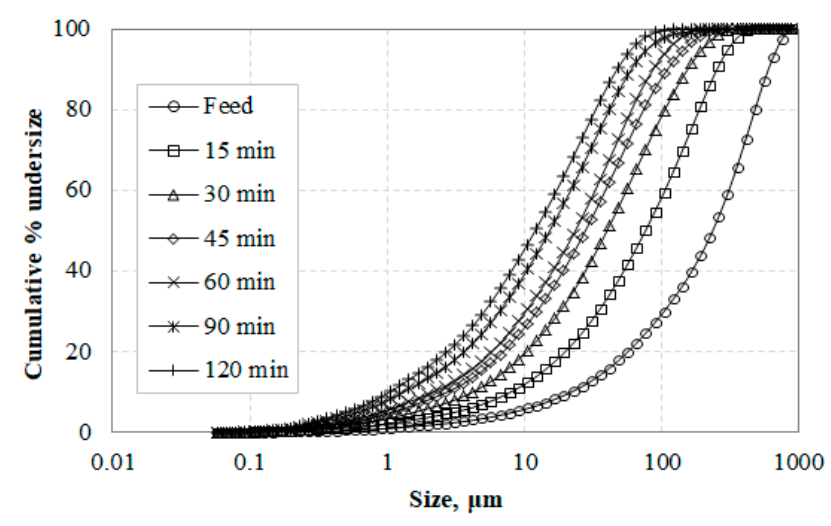

Figure 2. Variation of particle size distribution with grinding time.

In order to investigate the grinding kinetics of the raw slag seven representative sizes (222.3, $65.51,19.31,5.69,1.68,0.49$, and $0.15 \mu \mathrm{m}$ ) were selected, and the remaining volume (\%) fraction for each size after various grinding times was determined, as seen in Figure 3. The results indicate that the remaining fraction of each representative size decreases with increasing grinding time and the experimental data can be expressed by Equation (2), which confirms that grinding of slag exhibits non-first-order behavior and the reduction rate of each size is time dependent. The deviation from the first order is more evident for the larger particle sizes which are ground more efficiently than finer particles during grinding. The non-first-order grinding behavior is due to either mill conditions or material properties and has been reported in several earlier studies [22,34,61,62].

Table 3 presents the estimated parameters $K$ and $M$ by fitting the Alyavdin grinding kinetic equation to experimental data. This table also reveals the very good fitting curves, as indicated by the correlation coefficients $\left(R^{2}\right)$ values. Based on the grinding rate constant $(K)$ values, it is confirmed that grinding rate and consequently grinding efficiency increases when the particle size increases, but drops sharply to near zero values after prolonged grinding (Figure 3). The grinding time at which the grinding rate decreases to zero depends on particle size; the larger the particle size the faster the grinding rate drops to zero. $M$ values range between 0.652 and 1.110, indicating deviation from slope unity $(\mathrm{M}=1)$ and the first-order grinding kinetics of the population balance model. 


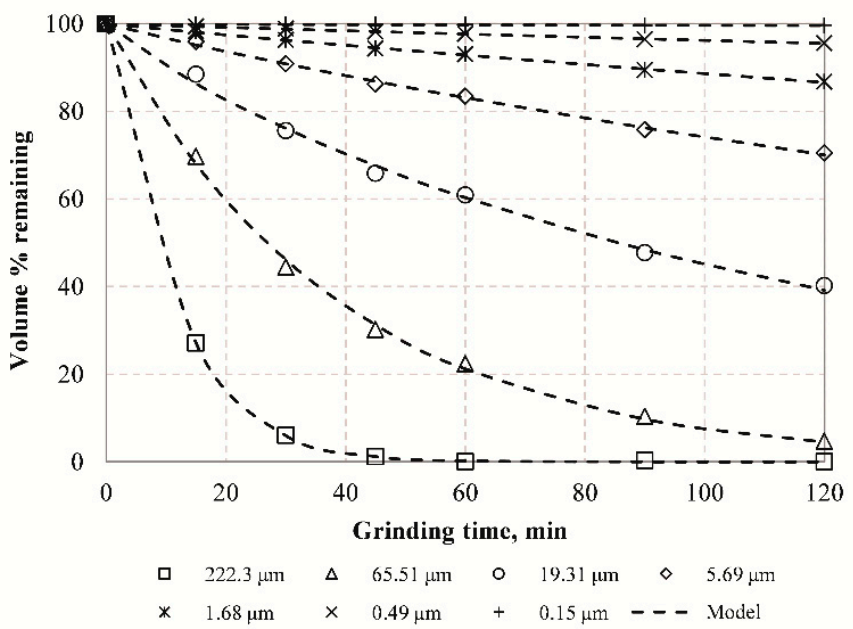

Figure 3. Remaining fraction (\% volume) for seven representative sizes vs. grinding time.

Table 3. Parameters of Alyavdin formula (Equation (2)) for seven representative sizes (mm).

\begin{tabular}{cccccccc}
\hline Parameter & $\mathbf{2 2 2 . 3} \mathbf{~} \mathbf{m}$ & $\mathbf{6 5 . 5 1} \mathbf{~} \mathbf{m}$ & $\mathbf{1 9 . 3 1} \mathbf{~} \mathbf{m}$ & $\mathbf{5 . 6 9} \mathbf{~} \mathbf{m}$ & $\mathbf{1 . 6 8} \mathbf{~} \mathbf{m}$ & $\mathbf{0 . 4 9} \mathbf{m m}$ & $\mathbf{0 . 1 5} \mathbf{~} \mathbf{m}$ \\
\hline $\mathrm{K}$ & 0.0645 & 0.0255 & 0.0132 & 0.0039 & 0.0015 & 0.0005 & 0.0002 \\
$\mathrm{M}$ & 1.110 & 1.004 & 0.890 & 0.943 & 0.954 & 0.952 & 0.652 \\
$\mathrm{R}^{2}$ (adj.) & 1.000 & 0.999 & 0.996 & 0.997 & 0.998 & 0.997 & 0.850 \\
\hline
\end{tabular}

\subsection{Particle Size and Specific Surface Area of Slag Products}

The characteristic diameters of the cumulative distributions, i.e. $d_{10}, d_{50}, d_{75}$, and $d_{90}$, which refer to particle sizes passing $10 \%, 50 \%, 75 \%$, or $90 \%$ cumulative undersize, were determined in order to investigate the fineness of the ground products for different grinding times (Table 4). In the LD technique particles are assumed to be spheres and therefore these characteristic diameters are typically the equivalent particle sizes (EPSs). This table also presents the SSA of the slag products determined by either the BET or LD techniques.

Table 4. Equivalent particle size and specific surface area of slag grinding products at different times.

\begin{tabular}{ccccccc}
\hline Grinding Time & $\mathbf{B E T}$ & $\mathbf{L D}$ & $\mathbf{d}_{\mathbf{1 0}}$ & $\mathbf{d}_{\mathbf{5 0}}$ & $\mathbf{d}_{\mathbf{7 5}}$ & $\mathbf{d}_{\mathbf{9 0}}$ \\
\hline $\mathbf{m i n}$ & $\mathbf{m}^{\mathbf{2}} \mathbf{k} \mathbf{k}$ & $\mathbf{m}^{\mathbf{2}} \mathbf{/ k g}$ & $\boldsymbol{\mu} \mathbf{m}$ & $\boldsymbol{\mu \mathbf { m }}$ & $\boldsymbol{\mu} \mathbf{m}$ & $\boldsymbol{\mu m}$ \\
\hline 15 & 930 & 221.5 & 7.9 & 75.9 & 163.0 & 252.2 \\
30 & 1200 & 316.3 & 4.2 & 39.9 & 88.8 & 153.8 \\
45 & 1435 & 416.2 & 2.7 & 27.8 & 62.5 & 109.5 \\
60 & 1598 & 486.3 & 2.1 & 23.4 & 51.8 & 86.2 \\
90 & 2160 & 681.5 & 1.3 & 15.2 & 35.2 & 59.9 \\
120 & 2260 & 780.4 & 1.0 & 11.9 & 28.1 & 47.1 \\
\hline
\end{tabular}

The results show that EPSs decrease during grinding, and no agglomeration is observed as indicated by the coarse part of the particle size distributions which continues to shift to finer sizes. This can be also seen from the $\mathrm{d}_{90}$ values (Table 4 ) which continue to decrease during grinding. More specifically, the $\mathrm{d}_{90}$ of slag grinding product obtained after 15 min of grinding was $252.2 \mu \mathrm{m}$ and reduced after prolonged grinding (120 $\mathrm{min}$ ) to $47.1 \mu \mathrm{m}$. Since surface area is intimately linked to particle size, the results of Table 4 show that the specific surface area increases during grinding. By comparing the different techniques, it is revealed that the measured surface areas with BET are almost three times bigger compared to those measured with $\mathrm{LD}$, and this indicates clearly that gas adsorption provides an essential bulk measurement of surface area as it can access surface features close to the size of nitrogen molecules. 
In order to investigate the grinding behavior of raw slag, non-linear regression analysis was carried out to correlate the equivalent particle size and grinding time (Figure 4).

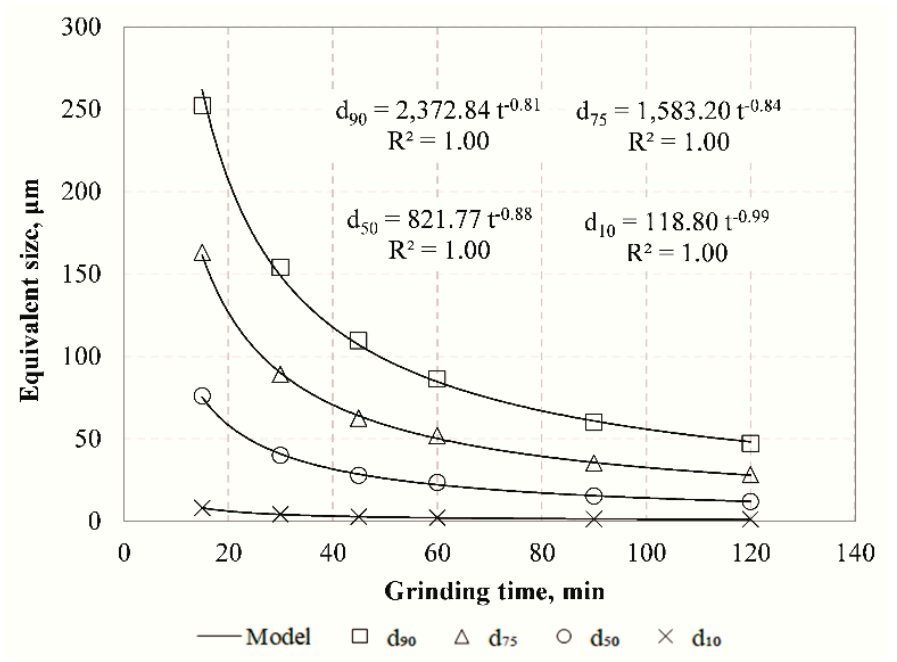

Figure 4. Equivalent particle size of slag products versus grinding time.

The results indicate that with the use of inverse exponential functions very strong correlations are obtained between EPSs and grinding time. It is evident that the reduction rate of particle size is constantly decreasing, and after prolonged grinding the particle size can reach a theoretical constant value which is defined as the grinding limit. This means that there is a product size that cannot be further reduced by the mill and all energy consumed beyond this point is considered as loss. Apart from various parameters affecting grinding limit, namely material type as well as process or machine parameters, its prediction is sensitive to the technique used. Figure 5 presents the evolution of median size $\left(\mathrm{d}_{50}\right)$ with grinding time in comparison with the particle size determined by the BET method using Equation (10).

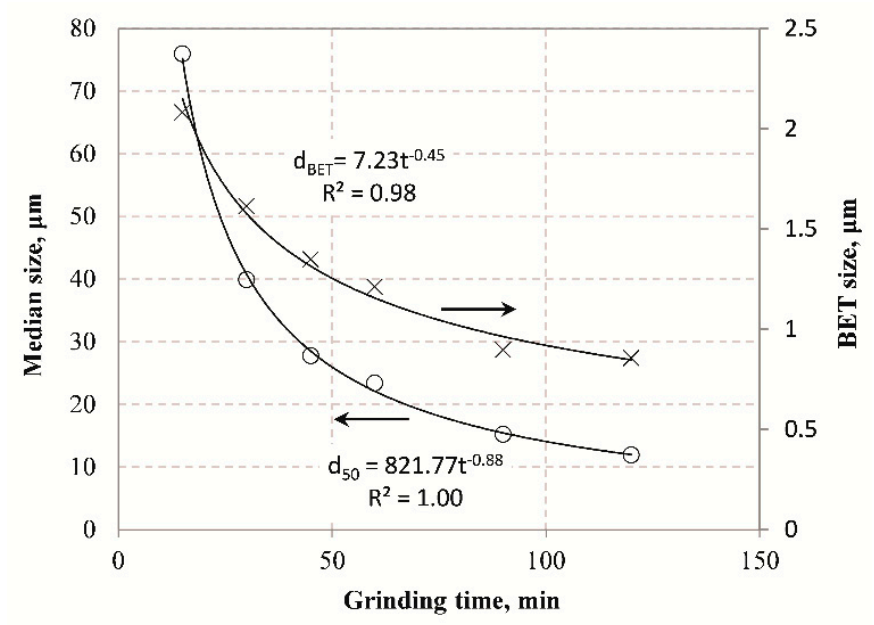

Figure 5. Evolution of median size $\left(\mathrm{d}_{50}\right)$ and Brunauer-Emmett-Teller (BET) size with grinding time.

In this equation the SSA values of BET provided in Table 4 were considered and the BET size at each grinding time was determined by using the relation $f / k=\pi / 6$. The results of Figure 5 show that in both cases the product particle size decreases with the grinding time, and very strong correlation between them is obtained with the use of inverse exponential function. However, the use of BET results in much finer particle sizes in comparison with LD. The results obtained from BET allow the determination of the true grinding limit as already mentioned in previous studies [63]. 


\subsection{Modeling of Particle Size Distributions of Grinding Product}

\subsubsection{Rosin-Rammler, Gates-Gaudin-Schuhmann and Logistic Distributions}

Rosin-Rammler, Gates-Gaudin-Schuhmann as well as Logistic distribution models were used to describe the particle size distribution of the slag products. Figure $6 a-c$ shows the PSDs obtained after grinding for various times and the fitted curves to data points using the RR (Equation (3)), Logistic model (Equation (5)) and GGS (Equation (7)), respectively. Non-linear least square analysis using the Solver tool of Microsoft Excel was used to fit the experimental data and the values of model parameters were estimated, as seen in Table 5.

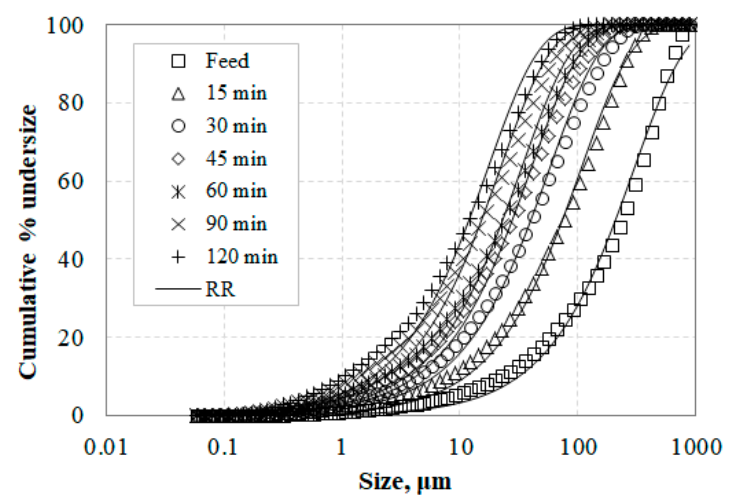

(a)

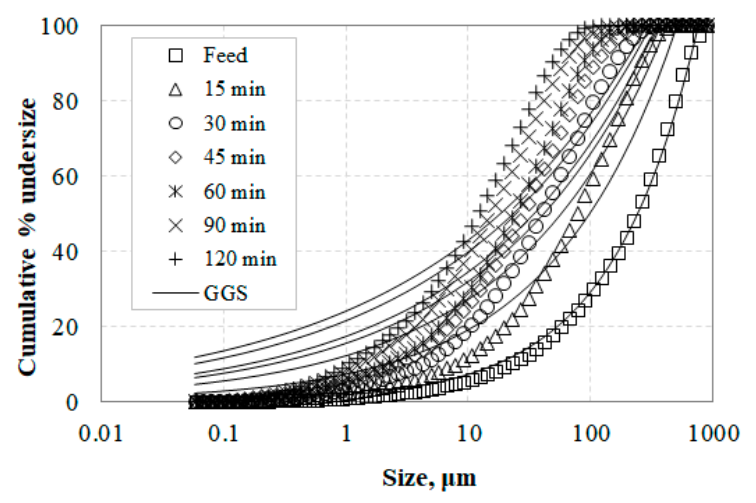

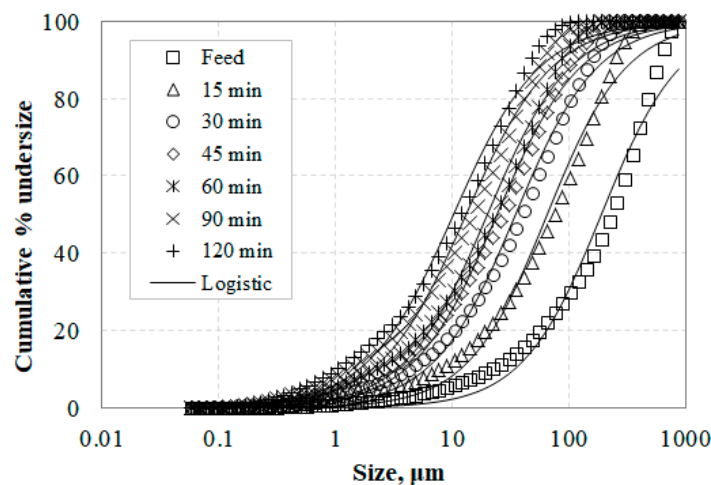

(b)

(c)

Figure 6. Particle size distribution of slag grinding products using the (a) Rosin-Rammler (RR) and (b) Logistic model, and (c) Gates-Gaudin-Schuhmann (GGS) distributions.

The accuracy of the model distributions was assessed using the adjusted correlation coefficient $\mathrm{R}^{2}$ (Ads.). The results indicate that $\mathrm{RR}$ is a particularly suitable model for representing particle size distributions obtained after grinding in a ball mill, and fits the experimental data better than the GGS and Logistic models. It is known that the PSD of materials generated by comminution can be dependent on a variety of factors such as the initial particle size and the physical properties of the material, as well as the comminution mechanisms applied by the machines. In this regard, the comminution forces acting on the particles during grinding change depending on the machine type, and this affects the product particle size distribution. For example, Taşdemir and Taşdemir [45] mention that the GGS model describes better the PSDs obtained after grinding of chromite ores by low energy events, i.e., jaw and cone crushing, while the RR model is more suitable for PSDs obtained by high energy events, i.e., hammer crushing and ball milling. 
Table 5. Model distribution parameters for the slag grinding products.

\begin{tabular}{cccccccc}
\hline \multirow{2}{*}{ Model } & \multirow{2}{*}{ Parameters } & \multicolumn{7}{c}{ Grinding Time (min) } \\
\cline { 3 - 8 } & & $\mathbf{1 5}$ & $\mathbf{3 0}$ & $\mathbf{4 5}$ & $\mathbf{6 0}$ & $\mathbf{9 0}$ & $\mathbf{1 2 0}$ \\
\hline \multirow{3}{*}{$\mathrm{RR}$} & $\mathrm{N}$ & 1.10 & 1.42 & 1.66 & 1.81 & 2.16 & 2.41 \\
& $\mathrm{x}^{\prime}$ & 116.8 & 81.5 & 66.5 & 60.1 & 47.6 & 41.7 \\
& $\mathrm{R}^{2}$ (Ads.) & 0.998 & 0.998 & 0.998 & 0.998 & 0.997 & 0.997 \\
\hline \multirow{3}{*}{ Logistic } & $\mathrm{x}_{50}$ & 65.42 & 35.06 & 24.29 & 20.12 & 13.21 & 10.30 \\
& $\Lambda$ & 1.28 & 1.24 & 1.22 & 1.23 & 1.18 & 1.18 \\
& $\mathrm{R}^{2}$ (Ads.) & 0.993 & 0.996 & 0.996 & 0.995 & 0.996 & 0.995 \\
\hline \multirow{3}{*}{ GGS } & $\mathrm{K}$ & 506.8 & 418.0 & 373.5 & 349.4 & 310.5 & 286.9 \\
& $\mathrm{M}$ & 0.42 & 0.35 & 0.32 & 0.30 & 0.27 & 0.25 \\
& $\mathrm{R}^{2}$ (Ads.) & 0.956 & 0.928 & 0.910 & 0.897 & 0.877 & 0.861 \\
\hline
\end{tabular}

Size parameters such as size modulus and uniformity index were also determined with the use of the RR model to characterize particle size distribution of the slag grinding products. As shown in Figure 7, the size modulus decreases with increasing grinding time, while the uniformity index becomes higher as grinding proceeds. These results indicate that the finer the product size the higher is the $n$ value, and the PSD becomes narrower. Very strong correlations $\left(R^{2}=1.00\right)$ are obtained with the use of exponential functions between size modulus or uniformity index and grinding time.

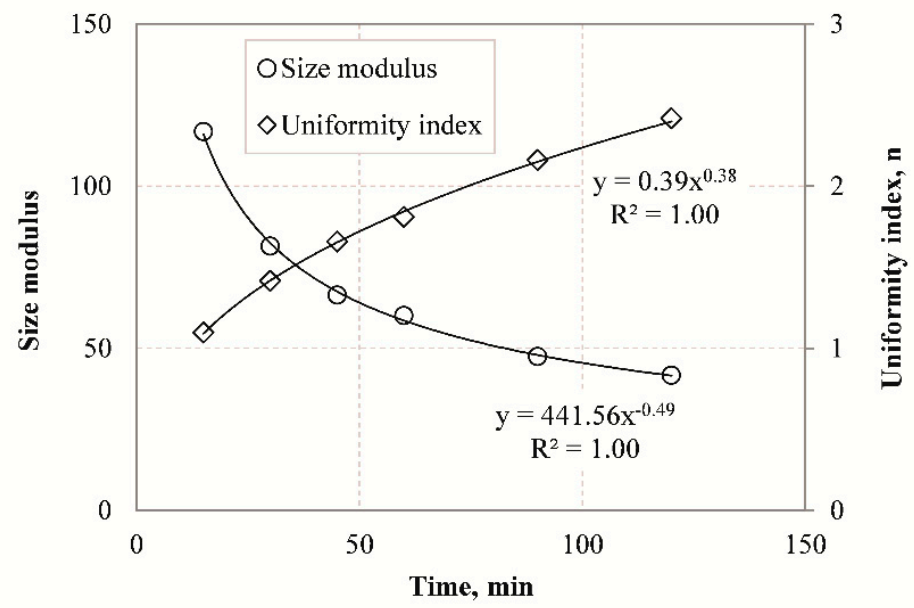

Figure 7. Size modulus and uniformity index versus grinding time using the RR model.

\subsubsection{Fractal Features of Products PSD}

Table 6 presents the estimated fractal dimensions $D$ of grinding products obtained after different grinding times using Equations (7) and (8). Linear regression analysis using the Solver tool of Microsoft Excel was used to fit the experimental data and the goodness of fit was assessed using the correlation coefficient $\mathrm{R}^{2}$. The results indicate that the values of $D$ range between 2.58 and 2.75 which are consistent with the findings of Carpinteri and Pugno [64], who reported that the fractal dimension from comminution experiments ranges between 2 and 3. As reported by Taşdemir [48], the grinding products of chromite ore had different ranges of $D$ values, depending on the type of machine used, which in turn affected their breakage mode. For example, in tumbling mills the ore is subjected to repeated forces and since the retention time is long they will eventually break. This results in higher $D$ values, indicating wider particle size distribution and bigger proportion of fines in mill products compared to other machines. Table 6 also shows that the value of $D$ increases with increasing grinding time, because as grinding proceeds more fines are produced. Due to fact that a large amount of energy is consumed for size reduction, especially for the production of very fine particles, the fractal dimension $D$ is also considered a factor of comminution efficiency. However, the goodness-of-fit $\left(R^{2}<0.957\right)$ 
indicates that the single fractal model may not represent the entire range of measured particle sizes. The application of the fractal model to PSDs yielded a certain lack-of-fit which is more apparent during long grinding periods. This is also confirmed from the log-log plot of particle size distribution of slag after $15 \mathrm{~min}$ of grinding (Figure 8). It can be seen that the measured data points cannot be represented by a straight line and a significant increase in slope at finer sizes (below $\sim 0.5 \mu \mathrm{m}$ ) is observed. To overcome this shortcoming, piecewise regression analysis by the quasi-Newton nonlinear estimation method was used to predict the size distributions derived. Figure 9 shows the presence of two different domains of particle sizes indicating that the PSDs of slag products may exhibit multi fractal character. These domains can be clearly identified by applying piecewise regression analysis, using Equation (9). Table 6 shows the estimated fractal dimensions $D_{1}$ and $D_{2}$ for the fine and coarse region of particle sizes, respectively. It is obvious that when piecewise regression analysis was applied to PSDs higher $\mathrm{R}^{2}$ are obtained compared to single linear regression. The fractal dimension of coarse region $\left(D_{2}\right)$ of particle sizes ranges between 2.29 and 2.49, and increases with increasing grinding time. However, the values of fractal dimension $D_{1}$ are negative and thus have no physical meaning. It is noted that Mandelbrot [65] introduced the fractal geometry to describe very irregular forms that cannot be represented by classical geometry. Fractal dimension is not necessarily an integer, and ranges between the values of Euclidean geometry for a point and volume and varies from 0 to 3 [48]. Thus, the fine region of particles cannot be represented by a fractal dimension and this may be due to limitations of the laser diffraction (LD) technique used, as already mentioned in previous studies [66,67]. The validity of particle size measurements in the submicron range using light scattering systems is questionable, and thus the slope of the fine region of particle size distributions may be misleading.

Table 6. Fractal dimensions calculated with the use of simple linear model and piecewise linear regression.

\begin{tabular}{cccccc}
\hline \multirow{2}{*}{ Grinding Time (min) } & \multicolumn{2}{c}{ Linear Regression } & \multicolumn{3}{c}{ Piecewise Regression } \\
\cline { 2 - 6 } & $\mathbf{D}$ & $\mathbf{R}^{\mathbf{2}}$ & $\mathbf{D}_{\mathbf{1}}$ & $\mathbf{D}_{\mathbf{2}}$ & $\mathbf{R}^{\mathbf{2}}$ \\
\hline 15 & 2.58 & 0.957 & -0.64 & 2.29 & 0.993 \\
30 & 2.65 & 0.929 & -1.33 & 2.32 & 0.989 \\
45 & 2.68 & 0.911 & -1.39 & 2.34 & 0.988 \\
60 & 2.70 & 0.899 & -1.45 & 2.37 & 0.989 \\
90 & 2.73 & 0.879 & -1.73 & 2.44 & 0.982 \\
120 & 2.75 & 0.863 & -1.92 & 2.49 & 0.980 \\
\hline
\end{tabular}

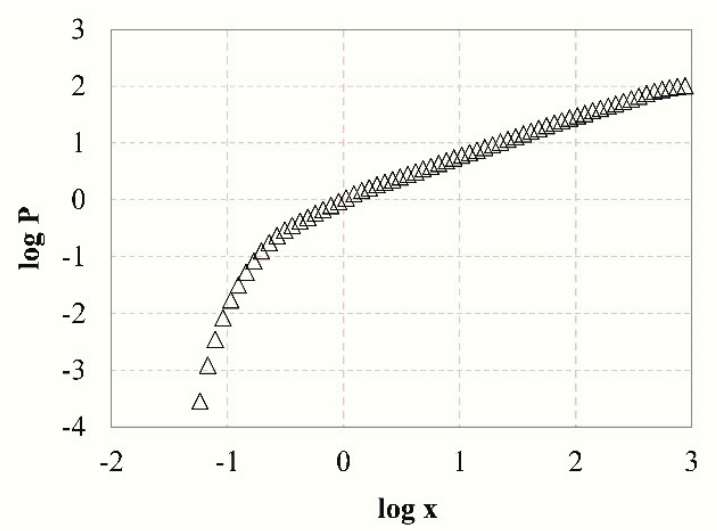

Figure 8. Log-log plot of particle size distribution of slag particles after 15 min of grinding. 


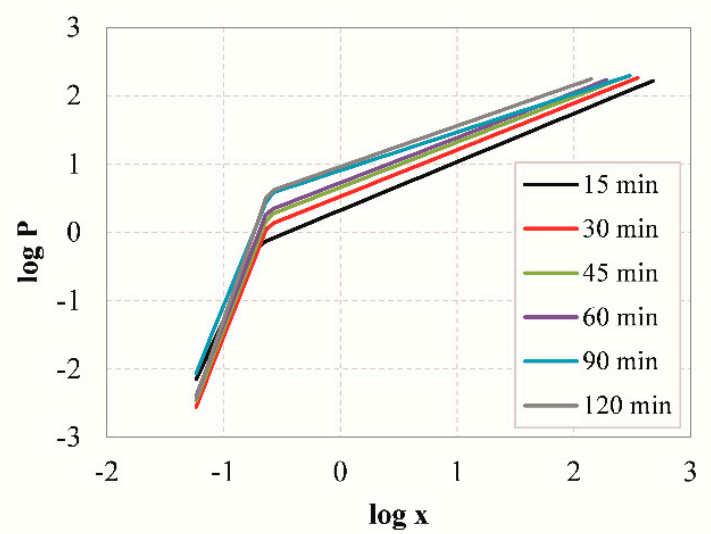

Figure 9. Log-log plots of particle size distributions of slag particles obtained after grinding for different times, using piecewise regression analysis.

\subsection{Alkali-Activation of Slag}

\subsubsection{Effect of Slag Particle Size and Curing Temperature}

In order to investigate the effect of slag particle size on the compressive strength of the produced AAMs, three different median sizes of slag particles were selected, namely 39.9, 23.4, and $11.9 \mu \mathrm{m}$, obtained after 30,60, and 120 min of grinding, respectively. The equivalent particle sizes of slag products are presented in Table 4. The other AAM synthesis conditions were the $\mathrm{H}_{2} \mathrm{O} / \mathrm{Na}_{2} \mathrm{O}$ molar ratio in the paste of 12.9 , the curing period of $24 \mathrm{~h}$ and the ageing period of seven days. The setting time of the paste depends on the particle size of the slag product and ranges between 3 and $9 \mathrm{~h}$ for the different grinding products tested. It was observed that the paste consisting of finer particles requires much shorter setting time compared to the paste consisting of coarser particles. This is due to the fact that the finer particles have larger specific surface area and react faster with the activating solution [68]. Figure 10 shows the compressive strength of the AAMs produced as a function of particle size and curing temperature $\left(60\right.$ or $\left.80^{\circ} \mathrm{C}\right)$.

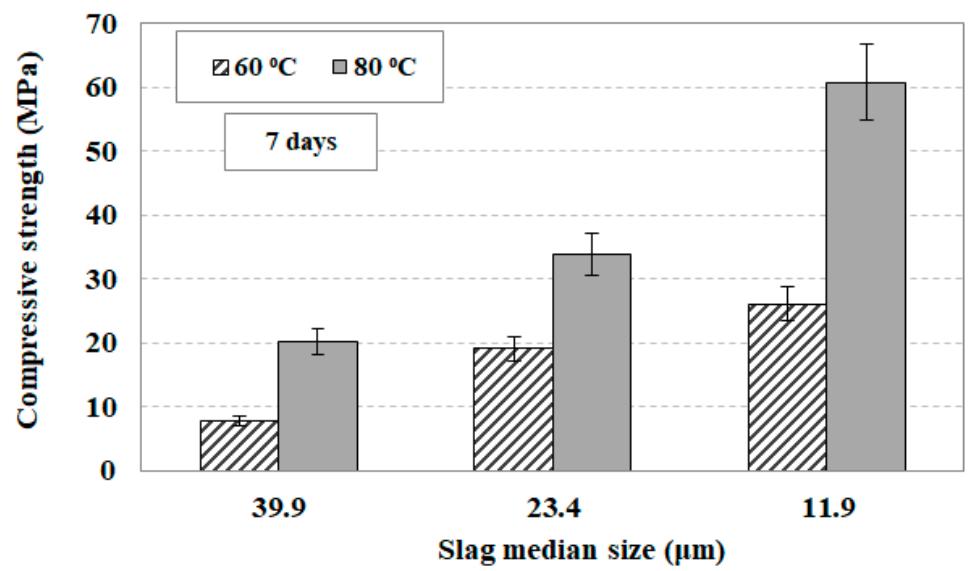

Figure 10. Effect of slag median size and curing temperature on the compressive strength of the produced alkali activated materials (AAMs). Synthesis conditions: molar ratio in the reactive paste $\mathrm{H}_{2} \mathrm{O} / \mathrm{Na}_{2} \mathrm{O} 12.9$, curing time $24 \mathrm{~h}$, ageing period seven days; median sizes of 39.9, 23.4, $11.9 \mu \mathrm{m}$ derived after 30, 60, and 120 min of grinding, respectively. Error bars indicate the standard deviation of three measurements.

It is seen from this data that at $60{ }^{\circ} \mathrm{C}$ when the median particle size of the slag grinding product decreases from 39.9 to $11.9 \mu \mathrm{m}$, and the compressive strength of the produced AAMs increases by $230 \%$, from 7.9 to $26.2 \mathrm{MPa}$. On the other hand, when the curing temperature increases to $80^{\circ} \mathrm{C}$ the 
produced AAMs acquire much higher compressive strength which increases by $200 \%$, from $20.2 \mathrm{MPa}$ to $60.8 \mathrm{MPa}$, when the median particle size decreases from 39.9 to $11.9 \mu \mathrm{m}$. These results indicate that when the raw material is finer, and thus has larger surface area, the reactions with the activating solution proceed faster, and thus the produced AAMs are denser and stronger [69,70]. It is noted that the increase of ageing period from seven to 28 days increases the compressive strength slightly, but the results are not provided in this study.

Other selected properties of the produced AAMs, namely, apparent density $\left(\mathrm{g} / \mathrm{cm}^{3}\right)$, porosity $(\%)$, and water absorption (\%) when different slag particle sizes were used are presented in Table 7. This table also shows the compressive strength of the AAMs produced under the conditions: $\mathrm{H}_{2} \mathrm{O} / \mathrm{Na}_{2} \mathrm{O}$ molar ratio in the reactive paste 12.9 , curing temperature $80^{\circ} \mathrm{C}$, curing time $24 \mathrm{~h}$, and ageing period seven days. It can be seen from this data that there is an evident difference in all properties when three median sizes of slag particles were used. The main difference was observed in porosity which decreased from 13.5 to $6.7 \%$ when the slag median size decreased from 39.9 to $11.9 \mu \mathrm{m}$, indicating that this property may have a significant effect on the compressive strength of the produced AAMs. A similar trend was observed for water absorption which decreased from 5.9 to $3.8 \%$ by taking into account the same median sizes. On the other hand, the apparent density of the AAMs increased from $2.28 \mathrm{~g} / \mathrm{cm}^{3}$ when slag with median size $39.9 \mu \mathrm{m}$ was used to $2.54 \mathrm{~g} / \mathrm{cm}^{3}$ when the median size was $11.9 \mu \mathrm{m}$. It is mentioned that the shrinkage of AAMs after curing at 60 or $80{ }^{\circ} \mathrm{C}$ was negligible. The reactivity of different slag products, as denoted by the concentration of $\mathrm{Al}$ and $\mathrm{Si}$ in solution after 8 mole/L NaOH leaching, and the respective Si/Al ratios, is shown in Table 8 . It is observed that when the slag median size decreases from 39.9 to $11.9 \mu \mathrm{m}$ the concentration of $\mathrm{Si}$ and $\mathrm{Al}$ in solution increases from 216 to $550 \mathrm{mg} / \mathrm{L}$ and 57 to $101.5 \mathrm{mg} / \mathrm{L}$, respectively. Thus, the Si/Al ratio also increases and reaches 5.4 when the median size of slag was $11.9 \mu \mathrm{m}$. These results justify the magnitude of the compressive strength values obtained.

Table 7. Selected properties of AAMs produced under the conditions $12.9 \mathrm{H}_{2} \mathrm{O} / \mathrm{Na}_{2} \mathrm{O}$, curing temperature $80^{\circ} \mathrm{C}$, curing time $24 \mathrm{~h}$, ageing period seven days.

\begin{tabular}{ccccc}
\hline Slag Median Size & Compressive Strength & Apparent Density & Porosity & Water Absorption \\
\hline$\mu \mathrm{m}$ & $\mathbf{M P a}$ & $\mathbf{g} / \mathbf{c m}^{\mathbf{3}}$ & $\mathbf{\%}$ & $\%$ \\
\hline 39.9 & 20.2 & 2.28 & 13.5 & 5.9 \\
23.4 & 33.8 & 2.37 & 10.6 & 4.5 \\
11.9 & 60.8 & 2.54 & 6.7 & 3.8 \\
\hline
\end{tabular}

Table 8. Concentration of $\mathrm{Si}$ and $\mathrm{Al}$ as well as $\mathrm{Si} / \mathrm{Al}$ ratio in solution after leaching of slag with different particle size with $\mathrm{NaOH}$.

\begin{tabular}{cccc}
\hline Slag Median Size & Si & Al & Si/Al \\
\cline { 1 - 3 } $\boldsymbol{\mu}$ & \multicolumn{2}{c}{$\mathbf{~ m g / L}$} & \\
\hline 39.9 & 216.0 & 57.0 & 3.8 \\
23.4 & 281.5 & 63.4 & 4.4 \\
11.9 & 550.0 & 101.5 & 5.4 \\
\hline
\end{tabular}

Figure 11 shows SEM-back-scattered electron (BSE) images of selected AAMs produced when different slag particle sizes were used, i.e., $39.9 \mu \mathrm{m}, 23.4 \mu \mathrm{m}$, and $11.9 \mu \mathrm{m}$. Overall, significant differences in the microstructure and the associated EDS analyses were observed among the AAMs studied. More specifically, the AAMs produced using slag with median size of $39.9 \mu \mathrm{m}$, obtained after $30 \mathrm{~min}$ of grinding, exhibit heterogeneous structures consisting of elongated and large in size unreacted slag particles (mostly diaspore, quartz, hedenbergite, and fayalite, in accordance with XRD analyses) surrounded by a porous and spongy inorganic gel matrix formed during alkali-activation (Figure 11a). EDS analysis of the inorganic gel (P1) revealed the abundance of $\mathrm{Ca}, \mathrm{Al}, \mathrm{Si}$, and Fe, as well as the 
presence of $\mathrm{Mg}$ and $\mathrm{Na}$ in lower quantities (provided by the alkaline activators $\mathrm{NaOH}$ and $\mathrm{Na}_{2} \mathrm{SiO}_{3}$ as well as after partial solubilization of the raw slag). However, well-defined cracks and voids are seen in the microstructure of AAMs produced using slag with a median size of $39.9 \mu \mathrm{m}$ due to incomplete gel formation, which probably explains the lower compressive strength obtained (20.2 MPa).
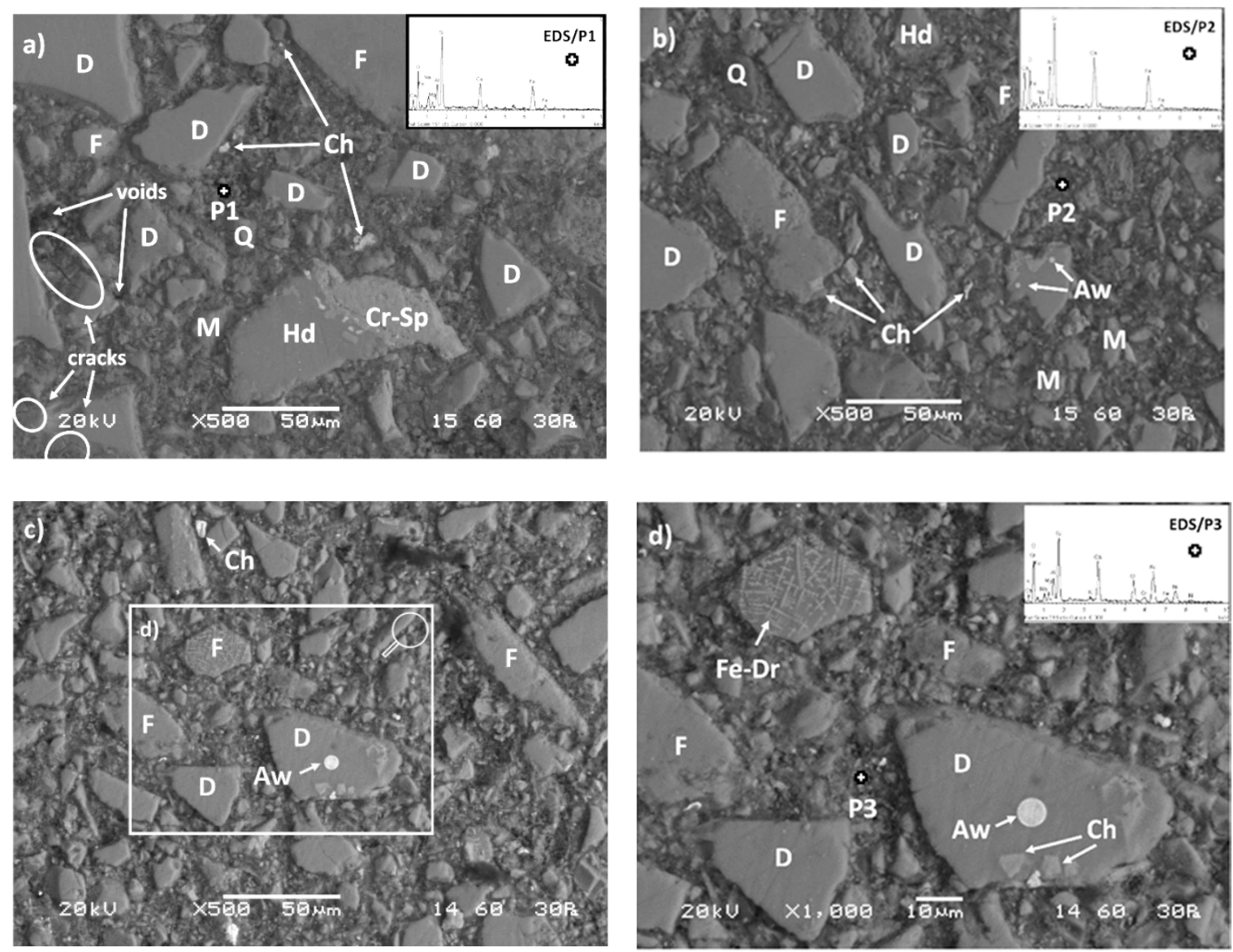

Figure 11. SEM-back-scattered electron (BSE) images of cross-sections of AAMs produced using slag particles with median size of (a) $39.9 \mu \mathrm{m}$, (b) $23.4 \mu \mathrm{m}$, and (c,d) $11.9 \mu \mathrm{m}$. The presence of unreacted compounds, crack propagation and void formation is seen in several spot locations. Q: Quartz $\left(\mathrm{SiO}_{2}\right), \mathrm{D}$ : Diopside $\left(\mathrm{CaMgSi}_{2} \mathrm{O}_{6}\right), \mathrm{M}$ : Magnetite $\left(\mathrm{Fe}_{3} \mathrm{O}_{4}\right), \mathrm{F}$ : Fayalite $\left(\mathrm{Fe}_{2} \mathrm{SiO}_{4}\right)$, $\mathrm{Hd}$ : Hedenbergite $\left(\mathrm{Ca}(\mathrm{Fe}, \mathrm{Mg})\left(\mathrm{SiO}_{3}\right)_{2}\right), \mathrm{Cr}-\mathrm{Sp}$ : Cr-Spinel, Fe-Dr: Ferrite dendrites, Ch: Chromite $\left(\mathrm{FeCr}_{2} \mathrm{O}_{4}\right)$, Aw: Awaruite $\left(\mathrm{Ni}_{3} \mathrm{Fe}\right)$.

On the other hand, after prolonged grinding of the slag and the production of finer particles, i.e., median size $23.4 \mu \mathrm{m}$ and $11.9 \mu \mathrm{m}$, almost negligible crack propagation and a highly dense and uniform/homogeneous inorganic matrix can be observed along the cross-sectional interfaces of the produced AAMs (Figure 11b,c, respectively). This microstructure suggests the formation of strong bonds due to polymeric reactions that took place between the alumino-silicate particles of the raw slag and the alkaline activators. In this context, particles with rounded edges or deteriorated are visible, indicating excessive dissolution of the raw slag by the attack of the alkaline solution. It also appears that the presence of finer slag particles, enhanced the dissolution of calcium ions present in diopside and hedenbergite.

In both AAMs produced using material obtained after prolonged grinding times (60 $\mathrm{min}$ and $120 \mathrm{~min}$ ), N-A-S-H and C-A-S-H gels coexist in the alkaline matrix and contribute to the formation of products with higher cohesion and strength [71,72]. As can be seen in Table 9, which shows the elemental composition and selected properties of AAMs, a greater conversion of the precursor material 
(raw slag) to polymeric compounds is achieved in the prolonged grinding (median size $23.4 \mu \mathrm{m}$ and $11.9 \mu \mathrm{m}$ ) compared to the AAMs produced from a slag median size of $39.9 \mu \mathrm{m}$ due to the higher $\mathrm{Ca} / \mathrm{Si}$ and $\mathrm{Al} / \mathrm{Si}$ ratios present, as indicated by EDS analyses (P2 and P3, respectively). As a result, higher solubilization of $\mathrm{Si}$ and $\mathrm{Al}$ from the raw slag was attained that subsequently caused the formation of denser reaction products and the increase in compressive strength, up to $60.8 \mathrm{MPa}$. On the other hand, the lower content of $\mathrm{Ca}$ along with the higher $\mathrm{Na}$ content detected in AAMs produced when slag with median size of $39.9 \mu \mathrm{m}$ was used, indicates that more N-A-S-H gel was formed, compared to C-A-S-H gel, and thus specimens with lower compressive strength was obtained (20.2 MPa). Finally, it is also interesting to mention that several other constituents were found in the alkaline matrix of the AAMs produced using slag particles with median size of $11.9 \mu \mathrm{m}$, such as $\mathrm{Cr}$ (up to $22 \%$ ), and $\mathrm{Ni}(10 \%)$ due to dissolution of chromite $\left(\mathrm{FeCr}_{2} \mathrm{O}_{4}\right)$ and awaruite $\left(\mathrm{Ni}_{3} \mathrm{~F}\right)$ particles, respectively. Figure $11 \mathrm{~d}$ (zoom of rectangular area of Figure 11c) shows the presence of chromite and awaruite as small single intergrown drops and inclusions embedded in the clinopyroxene (diopside) matrix as well as the development of ferrite dendrites in the fayalite matrix $[2,73]$.

Table 9. Elemental composition and selected properties of AAMs produced under the conditions $\mathrm{H}_{2} \mathrm{O} / \mathrm{Na}_{2} \mathrm{O}$ ratio 12.9 , curing temperature $80^{\circ} \mathrm{C}$, curing time $24 \mathrm{~h}$, ageing period seven days.

\begin{tabular}{cccccc}
\hline \multirow{2}{*}{$\begin{array}{c}\text { Slag Median Size } \\
\text { Used }(\mu \mathrm{m})\end{array}$} & $\begin{array}{c}\text { Representative } \\
\text { EDS Point }\end{array}$ & Ca/Si & A1/Si & Na/Si & \multirow{2}{*}{$\begin{array}{c}\text { Compressive } \\
\text { Strength (MPa) }\end{array}$} \\
\cline { 3 - 5 } & P1 & 0.27 & 0.19 & 0.31 & 20.2 \\
23.9 & P2 & 0.51 & 0.32 & 0.19 & 33.8 \\
11.9 & P3 & 0.79 & 0.41 & 0.14 & 60.8 \\
\hline
\end{tabular}

The AAMs produced using the same synthesis conditions were also characterized with XRD, as seen in Figure 12. The results indicate that the mineralogy of the AAMs produced using different slag median size have no significant differences. The specimens show a typical amorphous (broad hump between $20^{\circ}$ and $40^{\circ} 2 \theta$ ) to semi-crystalline composition consisting of several crystalline phases, i.e., quartz $\left(\mathrm{SiO}_{2}\right)$, hedenbergite $\left(\mathrm{Ca}(\mathrm{Fe}, \mathrm{Mg})\left(\mathrm{SiO}_{3}\right)_{2}\right)$, fayalite $\left(\mathrm{Fe}_{2} \mathrm{SiO}_{4}\right)$, diopside $\left(\mathrm{CaMgSi}_{2} \mathrm{O}_{6}\right)$, magnetite $\left(\mathrm{Fe}_{3} \mathrm{O}_{4}\right)$, and hatrurite $\left(\mathrm{Ca}_{3} \mathrm{SiO}_{5}\right)$.

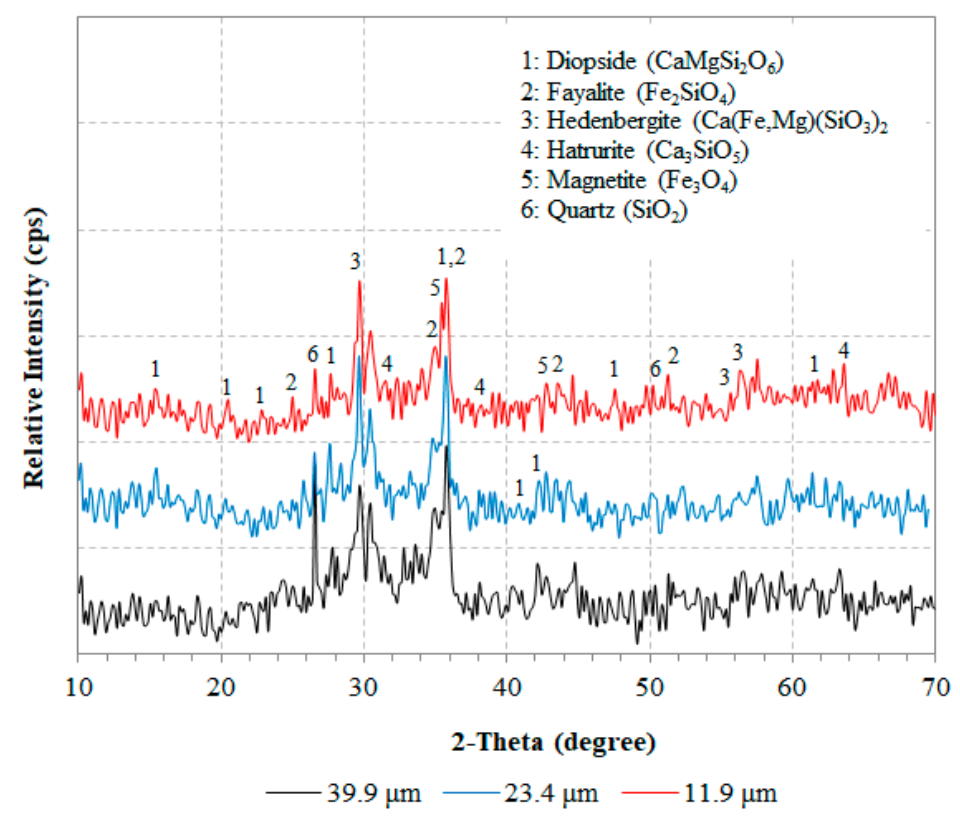

Figure 12. XRD patterns of produced AAMs when different median sizes of slag particles were used. Synthesis conditions were: molar ratio in the reactive paste $\mathrm{H}_{2} \mathrm{O} / \mathrm{Na}_{2} \mathrm{O} 12.9$, curing temperature $80{ }^{\circ} \mathrm{C}$, curing time $24 \mathrm{~h}$, ageing period seven days. 


\subsubsection{Prediction of the Compressive Strength of AAMs}

Figure 13 shows the effect of $d_{50}$ slag particle size and BET specific surface area (SSA) on the compressive strength (CS) of the AAMs produced under the conditions $\mathrm{H}_{2} \mathrm{O} / \mathrm{Na}_{2} \mathrm{O}$ molar ratio 12.9, heating $80^{\circ} \mathrm{C}$, curing period $24 \mathrm{~h}$, and ageing period seven days. Three different median sizes of slag were used, namely 39.9, 23.4 and $11.9 \mu \mathrm{m}$ corresponding to raw material obtained after 30,60 , and 120 min of grinding, respectively. Table 4 shows the respective values of SSA of the slag grinding products. Simple regression analysis with the use of Excel software was carried out to establish potential correlations between CS and $\mathrm{d}_{50}$, SSA and equations with the highest correlation coefficient $R^{2}$ were obtained. As seen in Figure 13, very strong correlation between CS and $d_{50}$ is obtained using inverse exponential equation, while CS is correlated very well with SSA using linear equations. The experimental data were validated with the execution of additional experiments using as raw material slag with a median size $15.2 \mu \mathrm{m}$ (90 min of slag grinding), and the results are given in Figure 13. The obtained equations are the following

$$
\begin{gathered}
C S=660 \cdot d_{50} 0^{-0.95} \quad R^{2}=0.99 \\
C S=0.04 \cdot S S A-30 \quad R^{2}=0.99
\end{gathered}
$$

where CS, SSA, and $d_{50}$ represent compressive strength (MPa), specific surface area $\left(\mathrm{m}^{2} / \mathrm{kg}\right)$, and median size $(\mu \mathrm{m})$, respectively.

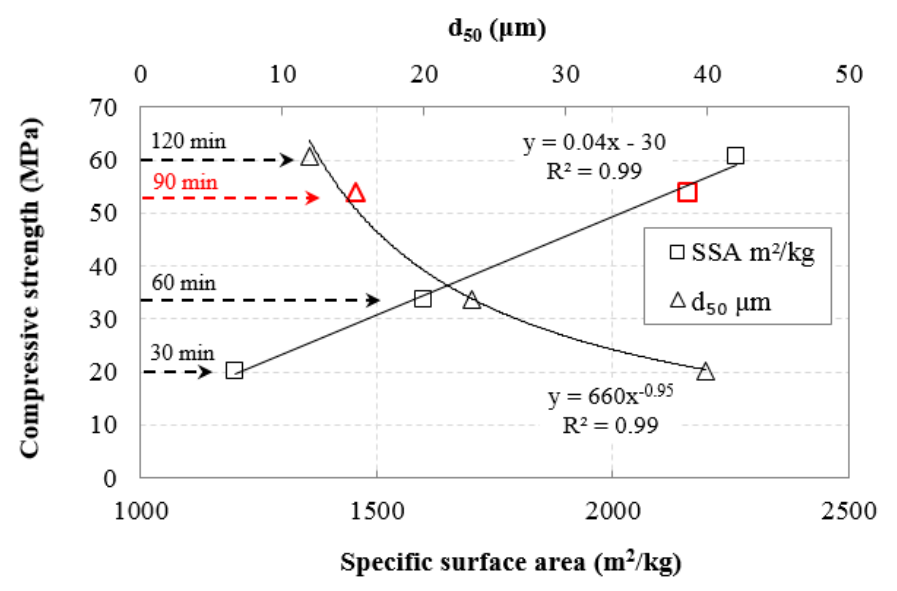

Figure 13. Correlations between compressive strength of AAMs produced and median size $\left(\mathrm{d}_{50}\right)$, BET specific surface area of slag.

\section{Conclusions}

The present experimental study studied the ball mill grinding kinetics of Polish slag in order to produce fractions that after alkali activation can be used for the production of AAMs with beneficial properties.

The results show that the particle size of slag products decreases with increasing grinding time, while particle agglomeration is not observed even after prolonged grinding (120 min). The equivalent particle sizes (EPSs) are very well correlated with grinding time, as derived through the use of inverse exponential functions. It is evident that the size reduction rate of particles is constantly decreasing and after prolonged grinding particle size can reach a constant value which is defined as the grinding limit. Among the different mathematical models used, i.e., Rosin-Rammler, Gates-Gaudin-Schuhmann, and Logistic distributions to simulate the particle size distribution, Rosin-Rammler was found to be the most suitable for the slag products. The piecewise regression analysis by the quasi-Newton nonlinear estimation method showed that the PSDs of slag products exhibit multifractal character. It is seen that 
when piecewise regression analysis was applied to PSDs higher $\mathrm{R}^{2}$ are obtained compared to single linear regression.

In addition, grinding of slag exhibits non-first-order behavior and the reduction rate of each size is time dependent. The deviation from the first order is more evident for the coarse particles indicating that these particles exhibit higher grinding efficiency than fine particles. Based on breakage rate constant $K$ values, it is shown that grinding efficiency increases when the particle size increases, but drops sharply near zero after prolonged grinding.

The results also indicate that the compressive strength of the produced AAMs is significantly affected by the slag particle size used. The finer particles of the raw slag have larger surface areas and react faster with the activating solution, and thus the produced AAMs acquire higher compressive strength, the maximum value of which reached $60.8 \mathrm{MPa}$ under the conditions slag median size $11.9 \mu \mathrm{m}, \mathrm{H}_{2} \mathrm{O} / \mathrm{Na}_{2} \mathrm{O} 12.9$ molar ratio, curing temperature $80{ }^{\circ} \mathrm{C}$, curing period $24 \mathrm{~h}$, and ageing period seven days. The results also indicate that the curing temperature is a crucial parameter during alkali activation, since higher temperatures accelerate activation reactions and thus AAMs with better mechanical properties are produced. The determination of selected properties of the produced AAMs revealed that porosity and water absorption decreased when the slag median size decreased, indicating that these properties have also an impact on the compressive strength. As expected, the apparent density $\left(\mathrm{g} / \mathrm{cm}^{3}\right)$ showed an inverse trend. Finally, correlations between particle size/specific surface area of the raw material and compressive strength of the produced specimens were established.

Author Contributions: E.P. designed and performed the experiments, critically analyzed results and wrote the paper. V.K. carried out experiments and analytical techniques and analyzed data. G.B. carried out SEM analysis and reviewed the paper. K.K. critically reviewed the experimental design, the analysis of the results and wrote the paper.

Funding: This research has received funding from the European Union's Horizon 2020 research and innovation programme under grant agreement No. 690088.

Conflicts of Interest: The authors declare no conflict of interest.

\section{References}

1. Mo, L.; Zhang, F.; Deng, M.; Jin, F.; Al-Tabbaa, A.; Wang, A. Accelerated carbonation and performance of concrete made with steel slag as binding materials and aggregates. Cem. Concr. Compos. 2017, 83, 138-145. [CrossRef]

2. Komnitsas, K.; Bartzas, G.; Karmali, V.; Petrakis, E.; Kurylak, W.; Pietek, G.; Kanasiewicz, J. Assessment of alkali activation potential of a Polish ferronickel slag. Sustainability 2019, 11, 1863. [CrossRef]

3. Chen, C.; Habert, G.; Bouzidi, Y.; Jullien, A. Environmental impact of cement production: Detail of the different processes and cement plant variability evaluation. J. Clean. Prod. 2010, 18, 478-485. [CrossRef]

4. Ali, M.; Saidur, R.; Hossain, M. A review on emission analysis in cement industries. Renew. Sustain. Energy Rev. 2011, 15, 2252-2261. [CrossRef]

5. Maharaj, C.; White, D.; Maharaj, R.; Morin, C. Re-use of steel slag as an aggregate to asphaltic road pavement surface. Cogent Eng. 2017, 4, 1416889. [CrossRef]

6. Komnitsas, K. Potential of geopolymer technology towards green buildings and sustainable cities. Procedia Eng. 2011, 21, 1023-1032. [CrossRef]

7. Penpolcharoen, M. Utilization of secondary lead slag as construction material. Cem. Concr. Res. 2005, 35, 1050-1055. [CrossRef]

8. Komnitsas, K.; Zaharaki, D. Geopolymerisation: A review and prospects for the minerals industry. Miner. Eng. 2007, 20, 1261-1277. [CrossRef]

9. Komnitsas, K.; Zaharaki, D.; Perdikatsis, V. Geopolymerisation of low calcium ferronickel slag. J. Mater. Sci. 2007, 42, 3073-3082. [CrossRef]

10. Shi, C.; Meyer, C.; Behnood, A. Utilization of copper slag in cement and concrete. Resour. Conserv. Recycl. 2008, 52, 1115-1120. [CrossRef]

11. Komnitsas, K.; Zaharaki, D.; Perdikatsis, V. Effect of synthesis parameters on the compressive strength of low-calcium ferronickel slag inorganic polymers. J. Hazard. Mater. 2009, 161, 760-768. [CrossRef] [PubMed] 
12. Mehta, A.; Siddique, R. Sustainable geopolymer concrete using ground granulated blast furnace slag and rice husk ash: Strength and permeability properties. J. Clean. Prod. 2018, 205, 49-57. [CrossRef]

13. Xu, H.; Van Deventer, J.S.J. The geopolymerisation of alumino-silicate minerals. Int. J. Miner. Process. 2000, 59, 247-266. [CrossRef]

14. Zaharaki, D.; Komnitsas, K.; Perdikatsis, V. Use of analytical techniques for identification of inorganic polymer gel composition. J. Mater. Sci. 2010, 45, 2715-2724. [CrossRef]

15. Perera, D.S.; Cashion, J.D.; Blackford, M.G.; Zhang, Z.; Vance, E.R. Fe speciation in geopolymers with Si/Al molar ratio of $\sim 2$. J. Eur. Ceram. Soc. 2007, 27, 2697-2703. [CrossRef]

16. Zaharaki, D.; Galetakis, M.; Komnitsas, K. Valorization of construction and demolition (C\&D) and industrial wastes through alkali activation. Constr. Build. Mater. 2016, 121, 686-693.

17. Arnold, M.C.; de Vargas, A.S.; Bianchini, L. Study of electric-arc furnace dust (EAFD) in fly ash and rice husk ash-based geopolymers. Adv. Powder Technol. 2017, 28, 2023-2034. [CrossRef]

18. Peys, A.; White, C.E.; Rahier, H.; Blanpain, B.; Pontikes, Y. Alkali-activation of CaO-FeOx-SiO 2 slag. Formation mechanism from in-situ X-ray total scattering. Cem. Concr. Res. 2019, 122, 179-188. [CrossRef]

19. Komnitsas, K.; Zaharaki, D.; Bartzas, G. Effect of sulphate and nitrate anions on heavy metal immobilisation in ferronickel slag geopolymers. Appl. Clay Sci. 2013, 73, 103-109. [CrossRef]

20. Alshaaer, M.; Zaharaki, D.; Komnitsas, K. Microstructural characteristics and adsorption potential of zeolitic tuff-Metakaolin geopolymers. Desalin. Water Treat. 2015, 56, 338-345. [CrossRef]

21. Djordjevic, N. Improvement of energy efficiency of rock comminution through reduction of thermal losses. Miner. Eng. 2010, 23, 1237-1244. [CrossRef]

22. Petrakis, E.; Stamboliadis, E.; Komnitsas, K. Identification of optimal mill operating parameters during grinding of quartz with the use of population balance modelling. KONA Powder Part. J. 2017, 34, $213-223$. [CrossRef]

23. Herbst, J.A.; Fuerstenau, D.W. Scale-up procedure for continuous grinding mill design using population balance models. Int. J. Miner. Process. 1980, 7, 1-31. [CrossRef]

24. Austin, L.G.; Klimpel, R.R.; Luckie, P.T. Process Engineering of Size Reduction: Ball Milling; SME-AIME: New York, NY, USA, 1984.

25. Ipek, H.; Göktepe, F. Determination of grindability characteristics of zeolite. Physicochem. Probl. Miner. Process. 2011, 47, 183-192.

26. Gupta, V.K.; Sharma, S. Analysis of ball mill grinding operation using mill power specific kinetic parameters. Adv. Powder Technol. 2014, 25, 625-634. [CrossRef]

27. Katubilwa, F.M.; Moys, M.H. Effect of ball size distribution on milling rate. Miner. Eng. 2009, 22, 1283-1288. [CrossRef]

28. Deniz, V. The effects of ball filling and ball diameter on kinetic breakage parameters of barite powder. Adv. Powder Technol. 2012, 23, 640-646. [CrossRef]

29. Olejnik, T.P. Selected mineral materials grinding rate and its effect on product granulometric composition. Physicochem. Probl. Miner. Process. 2013, 49, 407-418.

30. Shin, H.; Lee, S.; Jung, H.S.; Kim, J.-B. Effect of ball size and powder loading on the milling efficiency of a laboratory-scale wet ball mill. Ceram. Int. 2013, 39, 8963-8968. [CrossRef]

31. Petrakis, E.; Komnitsas, K. Correlation between material properties and breakage rate parameters determined from grinding tests. Appl. Sci. 2018, 8, 220. [CrossRef]

32. Mulenga, F.K.; Gharehgheshlagh, H.H.; Chehreghani, S. Assessing the dependency of selection function parameters with batch mill design. Adv. Powder Technol. 2019, 30, 242-251. [CrossRef]

33. Gupta, V.K. An appraisal of the energy-size reduction relationships for mill scale-up design. Adv. Powder Technol. 2019, 30, 73-84. [CrossRef]

34. Rajamani, R.K.; Guo, D. Acceleration and deceleration of breakage rates in wet ball mills. Int. J. Miner. Process. 1992, 34, 103-118. [CrossRef]

35. Bilgili, E.; Scarlett, B. Population balance modeling of non-linear effects in milling processes. Powder Technol. 2005, 153, 59-71. [CrossRef]

36. Barani, K.; Balochi, H. First-order and second-order breakage rate of coarse particles in ball mill grinding. Physicochem. Probl. Miner. Process. 2016, 52, 268-278.

37. Harris, C.C. The Alyavdin-Weibull Plot of Grinding Data and the Order of Kinetics. Powder Technol. 1973, 7, 123-127. [CrossRef] 
38. Beke, B. Process of Fine Grinding; Dr. W. Junk Publications: The Hague, The Netherlands, 1981.

39. King, R.P. Modeling and Simulation of Mineral Processing Systems; Butterworth-Heinemann: Oxford, UK, 2001; p. 416.

40. Allen, T. Powder Sampling and Particle Size Determination; Elsevier: Amsterdam, The Netherlands, $2003 ;$ p. 682.

41. Millán, H.; González-Posada, M.; Aguilar, M.; Domínguez, J.; Céspedes, L. On the fractal scaling of soil data. Particle-size distributions. Geoderma 2003, 117, 117-128. [CrossRef]

42. Zhong, W.; Yue, F.; Ciancio, A. Fractal behavior of particle size distribution in the rare earth tailings crushing process under high stress condition. Appl. Sci. 2018, 8, 1058. [CrossRef]

43. Menéndez-Aguado, J.M.; Peña-Carpio, E.; Sierra, C. Particle size distribution fitting of surface detrital sediment using the Swrebec function. J. Soils Sediments 2015, 15, 2004-2011. [CrossRef]

44. Osorio, A.M.; Menéndez-Aguado, J.M.; Bustamante, O.; Restrepo, G.M. Fine grinding size distribution analysis using the Swrebec function. Powder Technol. 2014, 258, 206-208. [CrossRef]

45. Taşdemir, A.; Taşdemir, T. A comparative study on PSD models for chromite ores comminuted by different devices. Part. Part. Syst. Charact. 2009, 26, 69-79. [CrossRef]

46. Lu, P.; Jefferson, I.F.; Rosenbaum, M.S.; Smalley, I.J. Fractal characteristics of loess formation: Evidence from laboratory experiments. Eng. Geol. 2003, 69, 287-293. [CrossRef]

47. Turcotte, D.L. Fractals and fragmentation. J. Geophys. Res. 1986, 91, 1921-1926. [CrossRef]

48. Taşdemir, A. Fractal evaluation of particle size distributions of chromites in different comminution environments. Miner. Eng. 2009, 22, 156-167. [CrossRef]

49. Petrakis, E.; Stamboliadis, E.; Komnitsas, K. Evaluation of the relationship between energy input and particle size distribution in comminution with the use of piecewise regression analysis. Part. Sci. Technol. 2017, 35, 479-489. [CrossRef]

50. Kierczak, J.; Neel, C.; Puziewicz, J.; Bril, H. The Mineralogy and weathering of slag produced by the smelting of lateritic Ni ores, Szklary, Southwestern Poland. Can. Miner. 2009, 47, 557-572. [CrossRef]

51. Ferraris, C.; Garboczi, E.J. Identifying improved standardized tests for measuring cement particle size and surface area. Transport. Res. Rec. 2013, 2342, 10-16. [CrossRef]

52. De Boer, G.B.J.; de Weerd, C.; Thoenes, D.; Goossens, H.W.J. Laser diffraction spectrometry: Fraunhofer diffraction versus Mie scattering. Part. Part. Syst. Charact. 1987, 4, 138-146. [CrossRef]

53. Xu, R. Particle Characterization: Light Scattering Methods; Kluwer Academic: Dordrecht, The Netherlands, 2002.

54. Kuila, U.; Prasad, M. Specific surface area and pore-size distribution in clays and shales. Geophys. Prospect. 2012, 61, 341-362. [CrossRef]

55. British Standards Institute. BS EN 1936: Natural Stone Test Methods. Determination of Real Density and Apparent Density and of Total and Open Porosity; NP EN 1936:2006; BSI: London, UK, 2007.

56. Kaya, E.; Hogg, R.; Kumar, S.R. Particle shape modification in comminution. KONA Powder Part. J. 2002, 20, 188-195. [CrossRef]

57. Hogg, R.; Turek, M.L.; Kaya, E. The Role of Particle Shape in Size Analysis and the Evaluation of Comminution Processes. Part. Sci. Technol. 2004, 22, 355-366. [CrossRef]

58. Petrakis, E.; Komnitsas, K. Effect of energy input in a ball mill on dimensional properties of grinding products. Min. Metall. Explor. 2019, 36, 803-816. [CrossRef]

59. Bailon-Poujol, I.; Bailon, J.-P.; L'Espérance, G. Ball-mill grinding kinetics of master alloys for steel powder metallurgy applications. Powder Technol. 2011, 210, 267-272. [CrossRef]

60. Zhao, J.; Wang, D.; Yan, P.; Li, W. Comparison of grinding characteristics of converter steel slag with and without pretreatment and grinding aids. Appl. Sci. 2016, 6, 237. [CrossRef]

61. Austin, L.G.; Bagga, P. An analysis of fine dry grinding in ball mills. Powder Technol. 1981, $28,83-90$. [CrossRef]

62. Fuerstenau, D.W.; Phatak, P.B.; Kapur, P.C.; Abouzeid, A.-Z.M. Simulation of the grinding of coarse/fine (heterogeneous) systems in a ball mill. Int. J. Miner. Process. 2011, 99, 32-38. [CrossRef]

63. Knieke, C.; Sommer, M.; Peukert, W. Identifying the apparent and true grinding limit. Powder Technol. 2009, 195, 25-30. [CrossRef]

64. Carpinteri, A.; Pugno, N. A fractal comminution approach to evaluate the drilling energy dissipation. Int. J. Numer. Anal. Methods Geomech. 2002, 26, 499-513. [CrossRef]

65. Mandelbrot, B.B. The Fractal Geometry of Nature; Freeman: New York, NY, USA, 1982. 
66. Austin, L.G.; Yekeler, M.; Dumm, T.F.; Hogg, R. The kinetics and shape factors of ultrafine dry grinding in a laboratory tumbling ball mill. Part. Part. Syst. Charact. 1990, 7, 242-247. [CrossRef]

67. Hogg, R. Issues in particle size analysis. KONA Powder Part. J. 2008, 26, 81-93. [CrossRef]

68. Traven, K.; Češnovar, M.; Ducman, V. Particle size manipulation as an influential parameter in the development of mechanical properties in electric arc furnace slag-based AAM. Ceram. Int. 2019, 45, 22632-22641. [CrossRef]

69. Heah, C.Y.; Kamarudin, H.; Mustafa, A.L.; Bakri, A.M.; Binhussain, M.; Luqman, M.; Khairul Nizar, I.; Ruzaidi, C.M.; Liew, Y.M. Effect of Curing Profile on Kaolin-based Geopolymers. Phys. Procedia 2011, 22, 305-311. [CrossRef]

70. Yahya, Z.; Abdullah, M.M.A.B.; Hussin, K.; Ismail, K.N.; Razak, R.A.; Sandu, A.V. Effect of Solids-To-Liquids, $\mathrm{Na}_{2} \mathrm{SiO}_{3}-\mathrm{To}-\mathrm{NaOH}$ and Curing Temperature on the Palm Oil Boiler Ash ( $\mathrm{Si}+\mathrm{Ca}$ ) Geopolymerisation System. Materials 2015, 8, 2227-2242. [CrossRef]

71. Yip, C.K.; Lukey, G.C.; Van Deventer, J.S.J. Coexistence of geopolymeric gel and calcium silicate hydrate at the early stage of alkali activation. Cem. Concr. Res. 2005, 35, 1688-1697. [CrossRef]

72. Peng, H.; Cui, C.; Liu, Z.; Cai, C.S.; Liu, Y. Synthesis and reaction mechanism of an alkali-activated metakaolin-slag composite system at room temperature. J. Mater. Civ. Eng. 2019, 31, 04018345. [CrossRef]

73. Parbhakar-Fox, A.; Gilmour, S.; Fox, N.; Olin, P. Geometallurgical Characterization of Non-Ferrous Historical Slag in Western Tasmania: Identifying Reprocessing Options. Minerals 2019, 9, 415. [CrossRef]

(C) 2019 by the authors. Licensee MDPI, Basel, Switzerland. This article is an open access article distributed under the terms and conditions of the Creative Commons Attribution (CC BY) license (http://creativecommons.org/licenses/by/4.0/). 